\title{
Risk Factors for Mortality in Children with Hospital- Acquired Pneumonia in Dr. Soetomo General Hospital Surabaya
}

\author{
Diska Hanifah Nurhayati ${ }^{1 *}$, Retno Asih Setyoningrum², Arie Utariani ${ }^{3}$, Ira Dharmawati ${ }^{2}$ \\ ${ }^{1}$ Faculty of Medicine, Universitas Airlangga, Surabaya, Indonesia. \\ ${ }^{2}$ Department of Pediatrics, Faculty of Medicine, Universitas Airlangga/Dr. Soetomo General Hospital, Surabaya, \\ Indonesia. \\ ${ }^{3}$ Department of Anesthesiology and Reanimation, Faculty of Medicine, Universitas Airlangga/Dr. Soetomo General \\ Hospital, Surabaya, Indonesia.
}

\section{ARTICLE INFO}

Article history:

Received 13 April 2021

Accepted 6 May 2021

Available online 31 May 2021

\section{Keywords:}

Hospital-acquired pneumonia,

Risk factor,

Mortality,

Children.

\begin{abstract}
Introduction: Hospital-Acquired Pneumonia (HAP) is a nosocomial pneumonia that brings negative impacts, such as prolonged hospital stay and increased cost. Previous studies often discussed about the risk factors of HAP mortality in adult patients rather than in children. This study aimed to analyze the risk factors of mortality in children with HAP.

Methods: This was a retrospective observational analytic study using cross sectional method with total sampling. A total of 73 children were enrolled in this study, consisted of inpatients at Pediatric Inpatient Room Dr. Soetomo General Hospital Surabaya who met the inclusion and exclusion criteria. Independent variables were gender, age, onset of HAP, length of stay (LOS), comorbidities, birth weight, type of breastfeeding, the use of mechanical ventilation (MV), and response to therapy. Dependent variable was mortality. The data were collected from medical records, which later were analyzed by bivariate and multivariate analysis.

Results: The mortality of children with HAP was $23.3 \%$. Bivariate analysis showed that age $(p=0.009)$, the use of MV $(p=0.029)$, and response to therapy $(p=0.036)$ were proven to affect mortality in children with HAP in Dr. Soetomo General Hospital Surabaya. In addition, the use of MV was the significant risk factor $(p=0.023)$ given by the multivariate analysis. Gender, onset of HAP, LOS, comorbidities, and type of breastfeeding were not proven to be the risk factors for mortality.

Conclusion: Mortality in children with HAP in Dr. Soetomo General Hospital Surabaya was significantly affected by children's age, the use of MV, and response to therapy. This information might be used as early signs and treatment strategies for children with HAP which lead to the decrease of hospital mortality.
\end{abstract}

\section{INTRODUCTION}

Pneumonia is the leading cause of mortality in children around the world, it is responsible for $16 \%$ of deaths of children under 5 years old in $2015 .{ }^{1}$ HospitalAcquired Pneumonia (HAP) is one type of pneumonia which occurs after 48 hours of hospitalization, it does not include incubation phase and is not related to mechanical ventilation (MV). ${ }^{2}$ The incidence of HAP in the United States was $1.6 \%$ and it was the most frequent infection taken place at the intensive care unit (ICU). ${ }^{3}$
As for pediatric patients, the incidence was $15-29 \%$, around $10-15 \%$ of all nosocomial infections in children and $67 \%$ of all nosocomial infections happened in pediatric intensive care unit (PICU). ${ }^{4-6}$ HAP in critically ill children brought negative impacts on clinical outcomes and economy, prolonged the use of MV, extended the duration of ICU stay, and might increase the cost and hospital mortality rate. ${ }^{7}$ The mortality rate of adult patients with HAP was $14,4 \%$ until $48,5 \% .^{8}$

*Correspondence: diska.hanifah.nurhayati-2017@fk.unair.ac.id 
This increase of mortality and morbidity was associated with the risk of having multi-drug resistant (MDR) organism as causative pathogen. ${ }^{2}$ According to previous study, other risk factors related to mortality of adult patients with HAP were the use of MV, duration of treatment, acute kidney injury, and hematologic disorders as comorbidities. ${ }^{8}$ Another study reported that inadequate empirical antibiotic therapy, Simplified Acute Physiology Score (SAPS), and more than one organs failure are also related to mortality of nosocomial pneumonia. ${ }^{9}$ Nevertheless, study about those risk factors are rarely observed in children although the incidence is quite high. Therefore, this study aimed to analyze the risk factors for mortality in children with HAP in Dr. Soetomo General Hospital Surabaya as the tertiary hospital.

\section{METHODS}

This observational retrospective study used cross sectional method and total sampling of the patients at Dr. Soetomo General Hospital Surabaya. The sampling was conducted through medical records. All pediatric inpatients aged 1 month-18 years old with HAP were included among other pneumonia patients admitted between January 2016 and December 2019. Children who used the MV before HAP signs and symptoms appeared were excluded in the study. Medical records used were ones that met the inclusion and exclusion criteria.

Pneumonia was defined according to World Health Organization (WHO) ${ }^{10}$ by observing child's respiration rate, the presence of cough or breathing difficulty, chest indrawing, and fever. HAP diagnosis is done by the main doctor who consulted with pediatric respirologist if necessary. The risk factor variables studied were gender, age, onset of HAP, length of stay (LOS), comorbidities, birth weight, type of breastfeeding, the use of MV, and response to therapy. Gender was differentiated as male and female. Age was the child's lifetime from birth until HAP signs and symptoms emerged, it was classified into two groups of $\leq 5$ years old and $>5$ years old based on epidemiological findings of the pneumonia incidence. Onset of HAP was the time from admission to the presence of pneumonia clinical signs and symptoms. There were two types of the onset, early-onset if the signs and symptoms appear within 5 days of admission, and late-onset if it appears after 5 days of admission or more. ${ }^{2}$ LOS was the hospitalization duration from admission until hospital discharge or death, with the cutoff for prolonged hospital stay was $>25$ days.

Comorbidities were the presence of other diseases at the same time along with HAP, including the initial diagnosis when admitted to hospital. They were grouped based on organ system disorder such as hematooncology, cardiology, neurology, gastrology, nephrology, and respiratory diseases. The number of diseases were counted in each group. Birth weight was child's weight measured right after birth and were written in medical record. Normal birth weight measured around 2,500-4,000 g, and low birth weight (less than $2,500 \mathrm{~g}$ ) or macrosomia (above 4,000 g) indicated an abnormal birth weight. ${ }^{11,12}$ Type of breastfeeding was feeding practice which the child had received during its first 6 months. Exclusive breastfeeding meant the child only received breast milk without other food/drink/water for 6 months of life, and predominant breastfeeding meant the child also received other liquids beside breast milk. ${ }^{13}$ The use of MV was when the patient used mechanical breathing assistance because of decreased respiratory function during the time after HAP diagnosis. Response to therapy was clinical response that could be observed in 48-72 hours after initial treatment. The parameters were axillary temperature, respiration, and chest indrawing. Mortality was the outcome of hospital death of the pediatric patient.

Numerical and categorical variables were presented as median (IQR) and $\mathrm{n}(\%)$. This study compared the risk factors between non-survivor and survivor and used $X^{2}$-test or Fisher's exact test as bivariate analysis to find the correlation between independent and dependent variables. Significant variables performed in bivariate analysis was continued to be explored in multivariate analysis using logistic regression. Two-sided $\alpha$ of less than 0.05 was statistically significant and the statistical analysis was performed with IBM SPSS Statistic (version 25). The study had the ethical clearance published by Medical Research Ethics Committee of Dr. Soetomo General Hospital Surabaya.

\section{RESULTS}

From the total of 1,008 pediatric patients with pneumonia hospitalized in Dr. Soetomo General 
Hospital Surabaya, 88 of them were HAP patients. After excluding patients that did not have required data, 73 inpatients were included in the study. There were 17 patients who died during hospitalization which was the non-survivor group and 56 were discharged with further outpatient setting, which was the survivor group. Mortality rate was $23.3 \%$ among children who developed HAP.

Median of age was 16.0 months (IQR 3.5 - 73.5) ranging from 1 month until 191 months (15 years) old. Most of the patients were males and almost all of the patients had comorbidities (Table 1). The three most frequent comorbidities were hematooncologic, cardiologic, and neurologic disorders, consecutively. Details for the type of diseases were presented in Table 2. 26 out of 34 patients had the signs and symptoms for pneumonia after 5 days of admission (late-onset), the median of onset duration for 34 patients was 15.5 days (IQR $5.5-29.3$ ). There were 26 out of 72 patients who experienced prolonged LOS up to 25 days (Table 1).
The median of birth weight data of 69 patients was $3,000 \mathrm{~g}$ (IQR 2,600 - 3,235) and 57 of them had abnormal birth weight $(<2,500 \mathrm{~g}$ or $>4,000 \mathrm{~g})$. There were only 32 out of 70 patients who had exclusive breastfeeding history. 9 patients were in need of MV and 5 of them $(56 \%)$ died. Therefore, only 65 patients' response to therapy could be observed. $61.5 \%$ of the patients did not show clinical improvement (no response) and $86 \%$ of the non-survivor group were patients who did not respond to therapy.

In bivariate analysis, age $(p=0.009)$, the use of MV ( $p=0.029)$, and response to therapy $(p=0.036)$ were risk factors associated to mortality in children with HAP. In the other hand, gender, onset of HAP, LOS, comorbidities (hematologic, cardiologic, and neurologic disorders), birth weight, and type of breastfeeding were not associated with mortality. The odds of hospital mortality were higher in patients who used MV and did not response to therapy (Table 3).

Table 1. Patients' characteristics

\begin{tabular}{|c|c|c|c|}
\hline Characteristics & $\begin{array}{c}\text { Total } \\
(\mathrm{n}=73)\end{array}$ & $\begin{array}{c}\text { Non-survivor } \\
(\mathrm{n}=17)\end{array}$ & $\begin{array}{c}\text { Survivor } \\
(\mathrm{n}=56)\end{array}$ \\
\hline \multicolumn{4}{|l|}{ Gender } \\
\hline - Male & $40(55 \%)$ & $7(41 \%)$ & $33(59 \%)$ \\
\hline - Female & $33(45 \%)$ & $10(59 \%)$ & $23(41 \%)$ \\
\hline Age, month & $16.0(3.5-73.5)$ & $72.0(2.5-107.0)$ & $12.0(3.3-37.0)$ \\
\hline - $\leq 5$ years old & $54(74 \%)$ & $8(47 \%)$ & $46(82 \%)$ \\
\hline - $\quad>5$ years old & $19(26 \%)$ & $9(53 \%)$ & $10(18 \%)$ \\
\hline Onset of HAP, day & $15.5(5.5-29.3)$ & $17.0(14.0-23.5)$ & $15.0(4.0-30.0)$ \\
\hline - Late-onset & $26 / 34(76.5 \%)$ & $8 / 9(89 \%)$ & $18 / 25(72 \%)$ \\
\hline - Early-onset & $8 / 34(23.5 \%)$ & $1 / 9(11 \%)$ & $7 / 25(28 \%)$ \\
\hline LOS & $16.0(8.3-30.8)$ & $18.0(5.0-29.0)$ & $16.0(9.0-31.0)$ \\
\hline - $\quad>25$ days & $26 / 72(36 \%)$ & $5(29 \%)$ & $21 / 55(38 \%)$ \\
\hline - $\leq 25$ days & $46 / 72(64 \%)$ & $12(71 \%)$ & $34 / 55(62 \%)$ \\
\hline Comorbidities & $72(99 \%)$ & $16(94 \%)$ & $56(100 \%)$ \\
\hline - Hematooncology & $40(55 \%)$ & $12(71 \%)$ & $28(50 \%)$ \\
\hline - Cardiology & $27(37 \%)$ & $8(47 \%)$ & $19(34 \%)$ \\
\hline - Neurology & $23(32 \%)$ & $3(18 \%)$ & $20(36 \%)$ \\
\hline - Gastrology & $22(30 \%)$ & $2(12 \%)$ & $20(36 \%)$ \\
\hline - Nephrology & $11(15 \%)$ & $2(12 \%)$ & $9(16 \%)$ \\
\hline - Respirology & $14(19 \%)$ & $3(18 \%)$ & $11(20 \%)$ \\
\hline Birth weight, gram & $3,000(2,600-3,235)$ & $2,950(2,500-3,075)$ & $3,000(2,700-3,350)$ \\
\hline - $\quad<2,500$ and $>4,000$ & $57 / 69(83 \%)$ & $14 / 16(87,5 \%)$ & $43 / 53(81 \%)$ \\
\hline - $2,500-4,000$ & $12 / 69(17 \%)$ & $2 / 16(12.5 \%)$ & $10 / 53(19 \%)$ \\
\hline \multicolumn{4}{|l|}{ Type of breastfeeding } \\
\hline - $\quad$ Predominant breastfeeding & $38 / 70(54 \%)$ & $9(53 \%)$ & $29 / 53(55 \%)$ \\
\hline - Exclusive breastfeeding & $32 / 70(46 \%)$ & $8(47 \%)$ & $24(45 \%)$ \\
\hline The use of MV & $9 / 72(12.5 \%)$ & $5(29 \%)$ & $4 / 55(7 \%)$ \\
\hline \multicolumn{4}{|l|}{ Response to therapy } \\
\hline - Not responding & $40 / 65(61.5 \%)$ & $12 / 14(86 \%)$ & $28 / 51(55 \%)$ \\
\hline - Responding & $25 / 65(38.5 \%)$ & $2 / 14(14 \%)$ & $23 / 51(45 \%)$ \\
\hline
\end{tabular}

Data were median (IQR), n (\%), or n/N (\%). HAP: Hospital-Acquired Pneumonia, LOS: length of stay, MV: mechanical ventilation. 
Table 2. Patients' comorbidities

\begin{tabular}{ll}
\hline \multicolumn{1}{c}{ Group } & Diseases \\
\hline Hematooncology & Anemia (unspecified), anemia of iron deficiency, anemia of chronic disease, ALL, AML, \\
Cardiology & leukocytosis, thrombocytopenia, febrile neutropenia, rhabdomyosarcoma, hemangioma, histiocytosis \\
& ASD, VSD, TAPVD, valve disorders, PDA, TOF, MPA dilatation, endocarditis, PH, PFO, \\
cardiomyopathy, pericardial abscess, pericardial effusion & Acute diarrhea, paralytic ileus, GERD, cholestasis, melena, anal fissure, post repair colon perforation \\
Geustrology & Hydrocephalus, meningocele, brain edema, epilepsy, status epilepticus, febrile seizure, \\
microcephaly, meningoencephalitis, encephalopathy, germinoma, hygroma, herpestic neuralgia \\
Nephrology & AKI, lupus nephritis, UTI, hydronephrosis, urolithiasis, Wilm's tumor \\
Respirology & Infant asthma, lung tuberculosis \\
Other & Developmental delay, Down syndrome, laryngomalacia, hypothyroid, electrolyte imbalance, \\
& malnutrition \\
\hline ALL: acute lymphoblastic leukemia, AML: acute myeloblastic leukemia, ASD: atrial septal defect, VSD: ventricular septal defect, \\
TAPVD: total anomalous pulmonary venous drainage, PDA: patent ductus arteriosus, TOF: tetralogy of Fallot, MPA: main \\
pulmonary artery, PH: pulmonary hypertension, PFO: patent foramen ovale, GERD: gastroesophageal reflux disease, AKI: acute \\
kidney injury, UTI: urinary tract infection
\end{tabular}

Table 3. Bivariate analysis

\begin{tabular}{|c|c|c|c|}
\hline Risk Factors & OR & $95 \% \mathrm{CI}$ & $P$ value \\
\hline \multicolumn{4}{|l|}{ Gender } \\
\hline $\begin{array}{ll}\text { - } & \text { Male } \\
\text { - } & \text { Female }\end{array}$ & 0.49 & $0.16-1.47$ & 0.198 \\
\hline \multicolumn{4}{|l|}{ Age } \\
\hline $\begin{array}{l}-\quad \leq 5 \text { years old } \\
\text { - } \quad>5 \text { years old }\end{array}$ & 0.19 & $0.60-0.62$ & 0.009 \\
\hline \multicolumn{4}{|l|}{ Onset of HAP } \\
\hline $\begin{array}{ll}\text { - } & \text { Late-onset } \\
\text { - } & \text { Early-onset }\end{array}$ & 3.11 & $0.36-29.7$ & 0.403 \\
\hline \multicolumn{4}{|l|}{ LOS } \\
\hline $\begin{array}{l}\text { - } \quad>25 \text { days } \\
\text { - } \quad \leq 25 \text { days }\end{array}$ & 0.63 & $0.19-2.02$ & 0.431 \\
\hline \multicolumn{4}{|l|}{ Comorbidities } \\
\hline - Hematooncology & 2.40 & $0.75-7.71$ & 0.135 \\
\hline - Cardiology & 1.73 & $0.58-5.21$ & 0.326 \\
\hline - Neurology & 0.39 & $0.09-1.50$ & 0.160 \\
\hline \multicolumn{4}{|l|}{ Birth weight, gram } \\
\hline $\begin{array}{l}\text { - } \quad<2,500 \text { and }>4,000 \\
\text { - } \quad 2,500-4,000\end{array}$ & 0.61 & $0.12-3.15$ & 0.718 \\
\hline \multicolumn{4}{|l|}{ Breastfeeding history } \\
\hline $\begin{array}{l}\text { - } \quad \text { Predominant breastfeeding } \\
\text { - Exclusive breastfeeding }\end{array}$ & 0.93 & $0.31-2.78$ & 0.898 \\
\hline $\begin{array}{l}\text { The use of MV } \\
\text { Response to therapy }\end{array}$ & 5.31 & $1.24-22.81$ & 0.029 \\
\hline $\begin{array}{ll}\text { - } & \text { Not responding } \\
\text { - } & \text { Responding }\end{array}$ & 4.93 & $1.00-24.30$ & 0.036 \\
\hline
\end{tabular}

$P$ value obtained from $X^{2}$ test or Fisher's exact test. OR: odds ratio, HAP: Hospital-Acquired Pneumonia, LOS: length of stay, MV: mechanical ventilation.

Multivariable analysis was performed in variables that had $p$ value $<0.25$ to see which variables significantly affected mortality. Five factors were incuded in logistic regression, namely gender, age, having hematooncologic and neurologic disorders as comorbidities, the use of MV, and response to therapy. The result can be seen in Table 3 .
The logistic regression model was statistically significant, carrying $X^{2}(6)=17,113$ with $p<0.05$. This model explained $35.8 \%$ (Nagelkerke $R^{2}$ ) of the variance in mortality and correctly classified $83.1 \%$ cases. The use of MV was the significant risk factor which associated with mortality $(\mathrm{p}=0.023)$. Children who used MV for breathing assistance were 11 times more likely to die compared to children who did not (Table 4). 
Table 4. Multivariate analysis

\begin{tabular}{lccc}
\hline \multicolumn{1}{c}{ Risk Factors } & OR & $95 \%$ CI & $P$ value \\
\hline Male (vs female) & 0.41 & $0.10-1.72$ & 0.223 \\
Age $\leq 5$ years old (vs $>$ 5 years old) & 0.44 & $0.08-2.44$ & 0.348 \\
Comorbidities (vs no comorbidity) & & $0.12-5.17$ & 0.811 \\
$\bullet \quad$ Hematooncology & 0.79 & $0.02-1.65$ & 0.129 \\
$\bullet \quad$ Neurology & 0.18 & $1.41-96.90$ & 0.023 \\
The use of MV (vs not using) & 11.68 & $0.90-34.24$ & 0.064 \\
Did not respond to therapy (vs responded) & 5.56 & & \\
\hline
\end{tabular}

$P$ value obtained from logistic regression. OR: odds ratio.

\section{DISCUSSION}

HAP doubled the duration of PICU stay, increased the length of MV usage, and increased mortality rate than in patients without HAP. ${ }^{7}$ The mortality in this study was $23.3 \%$ which corresponded with previous studies performed in adult and pediatric patients, ranging from $9.2 \%$ until $56 \% .^{7,8}$ This study found that there were more male patients than females. However, 10 (59\%) females were in the non-survivor group, slightly higher than male that reached $7(41 \%)$ patients. Gender had the possibility of affecting infectious disease incidence, including pneumonia. ${ }^{14}$ Arnold, et al. (2013) stated that adult females with Community-Associated Pneumonia (CAP) were more likely to have longer time to reach clinical improvement, but the difference of treatment between the two gender was still questionable. ${ }^{15}$ In this study, gender was not the risk factor associated with mortality in children with HAP. López-de-Andrés, et al. (2020) in their study also said that being female did not have association with mortality in CAP and HAP, but it did in patients with Ventilator-Associated Pneumonia (VAP). ${ }^{16}$ In CAP, there could be other factors correlated with gender which might result in the association with incidence and mortality, adult males tend to smoke more and develop respiratory disease. ${ }^{17}$

HAP was found mostly in children under 5 years old, about $74 \%$ of all patients in this study. $14.8 \%$ of them were in the non-survivor group and age was associated with mortality in children with HAP. It is known that pneumonia was the leading cause of death due to infection in children $<5$ years old. ${ }^{18}$ Age also influenced clinical overview in children, the disparity happened as consequence of anatomy and immunology immaturity in specific age groups. ${ }^{18}$ Ferdous, et al. (2018) said that younger infants ( $<6$ months) had greater risk for mortality than the older group that was associated with weaker immune system in infants if they did not have exclusive breastfeeding. ${ }^{19,20}$ Onset of HAP was not associated with mortality in children with HAP, although there were $89 \%$ of non-survivors who had lateonset HAP. Guidelines from American Thoracic Society and Infectious Diseases Society of America once stated that early-onset HAP had better prognosis than lateonset, because late-onset was reflected by multi-drug resistant causative pathogen. ${ }^{2}$ This was feared to cause inadequate initial treatment. ${ }^{2}$ Nevertheless, other study had similar finding with this study which stated that HAP onset did not statistically significant. ${ }^{8}$

Length of stay did not show association with mortality in children with HAP. From 17 non-survivors, $71 \%$ were patients hospitalized in $<25$ days. Mansour and Bendary (2012) reported that prolonged hospital stay was one of the risk factors for acquiring HAP. ${ }^{7}$ Almost all patients had comorbidities, 12 patients with hematooncologic disorders were in the non-survivor group. In immunocompromised adult patients with HAP, hematologic disorders and acute kidney injury were factors associated with mortality. ${ }^{8}$ Malignancy and shock were also in correlation with pneumonia mortality, especially VAP. ${ }^{21,22}$ In the contrary, this study did not find the association between comorbidities and mortality. The different results might be due to differences in sample group (child vs adult) and the comorbid impacts were varying on different age groups.

Around $83 \%$ of all patients had abnormal birth weight $(<2,500$ or $>4,000 \mathrm{~g})$ and $54 \%$ received predominant breastfeeding. According to Brown (1996), pneumonia mortality would decrease along with the increase of birth weight in children aged 1-5 years, but in different age group (6-11 months) the risk for mortality was the same in children with low birth weight (LBW) and >3,500 $\mathrm{g}^{23}$ Mortality were higher in predominant breastfeeding, because breast milk gave protective effect in infant $<9$ months against respiratory infection. ${ }^{24}$ In this study, birth weight and type of 
breastfeeding were not associated with mortality in children with HAP. In fact, LBW and predominant breastfeeding history were associated with the incidence of pneumonia. ${ }^{25,26}$ It might be caused by the treatment given after developing HAP that made this result, which more likely affected mortality and morbidity.

9 out of 72 patients were in need of MV and 5 of them died. MV was the significant factor associated with mortality in children with severe and more severe pneumonia. ${ }^{27} \mathrm{MV}$ dependence was also independent risk factor related to mortality in the study with CAP. ${ }^{28}$ This study found the same result as previous studies, where the use of MV significantly associated with mortality in children with HAP. The risk of mortality increased until 11 times higher in patients who had MV. The dependence promoted barotrauma, volumtrauma, or biotrauma, which lead to dangerous complication such as bronchopulmonary dysplasia (BPD). ${ }^{29}$ The last, response to therapy was found to have association with mortality. The conditions that would likely lead to mortality were acting the same as deterioration factor that worsen patients' clinical state in early treatment. ${ }^{2}$ Prolonged MV durations, respiratory failure, and other complications would hardly result in clinical improvement in adult. $^{2}$ In children with HAP, the conditions were respiration rate $>70 \mathrm{x} / \mathrm{min}$, lethargy/unconsciousness, and positive blood culture. ${ }^{30}$ It was feared that there were lack information in correlation between response to therapy and mortality, because generally response to therapy was observed simultaneously with mortality as the outcome.

This study was the first to analyze risk factors for mortality in children with HAP in Indonesia. It gave information that could be used as early signs and treatment strategies for children with HAP. The limitations of this study were small sample size and there were some available data from medical records that could not be included.

\section{CONCLUSION}

There was an association between variables according to the $p$ values. It is concluded that age, MV use, and response to therapy were the risk factors for mortality in children with HAP in Dr. Soetomo General Hospital Surabaya. On the other hand, gender, HAP onset, LOS, comorbidities, and type of breastfeeding were not proven to be the risk factors for mortality. Multivariate analysis also found that MV use was the significant risk factor for mortality.

\section{REFERENCES}

1. WHO. Pneumonia. Geneva, https://www.who.int/ en/news-room/fact-sheets/detail/pneumonia (2019, accessed 24 January 2021).

2. Society AT, America IDS of. Guidelines for the Management of Adults with Hospital-Acquired, Ventilator-Associated, and Healthcare-Associated Pneumonia. Am J Respir Crit Care Med 2005; 171: 388-416.

3. Leone M, Bouadma L, Bouhemad B, et al. Hospital-Acquired Pneumonia in ICU. Anaesthesia, Crit care pain Med 2018; 37: 83-98.

4. Zar HJ, Cotton MF. Nosocomial Pneumonia in Pediatric Patients: Practical Problems and Rational Solutions. Pediatr Drugs 2002; 4: 73-83.

5. Foglia E, Meier MD, Elward A. VentilatorAssociated Pneumonia in Neonatal and Pediatric Intensive Care Unit Patients. Clin Microbiol Rev 2007; 20: 409-25, table of contents.

6. Bigham MT, Amato R, Bondurrant $\mathrm{P}$, et al. Ventilator-Associated Pneumonia in the Pediatric Intensive Care Unit: Characterizing the Problem and Implementing a Sustainable Solution. J Pediatr 2009; 154: 582-587.e2.

7. Mansour MGE, Bendary S. Hospital-Acquired Pneumonia in Critically Ill Children: Incidence, Risk Factors, Outcome and Diagnosis with Insight on the Novel Diagnostic Technique of Multiplex Polymerase Chain Reaction. Egypt J Med Hum Genet 2012; 13: 99-105.

8. Sangmuang P, Lucksiri A, Katip W. Factors Associated with Mortality in Immunocompetent Patients with Hospital-acquired Pneumonia. J Glob Infect Dis 2019; 11: 13-18.

9. Lee S-C, Hua C-C, Yu T-J, et al. Risk Factors of Mortality for Nosocomial Pneumonia: Importance of Initial Anti-Microbial Therapy. Int J Clin Pract 2005; 59: 39-45.

10. WHO. Pocket Book of Hospital Care for Children: Guidelines for the Management of Common Illnesses with Limited Resources. Geneva: WHO Press, 2005.

11. WHO. International Statistical Classification of Diseases and Related Health Problems: 10th revision. 2nd ed. Geneva: World Health Organization, 2004.

12. Akanmode AM, Mahdy H. Macrosomia. Treasure Island (FL), 2021.

13. WHO. WHO | The World Health Organization's Infant Feeding Recommendation.

14. Barbagelata E, Cillóniz C, Dominedò C, et al. Gender Differences in Community-Acquired 
Pneumonia. Minerva Med 2020; 111: 153-165.

15. Arnold FW, Wiemken TL, Peyrani $\mathrm{P}$, et al. Outcomes in Females Hospitalised with Community-Acquired Pneumonia are Worse than in Males. Eur Respir J 2013; 41: 1135-1140.

16. López-de-Andrés A, Albaladejo-Vicente R, de Miguel-Diez $\mathrm{J}$, et al. Gender Differences in Incidence and In-Hospital Outcomes of Community-Acquired, Ventilator-Associated and Nonventilator Hospital-Acquired Pneumonia in Spain. Int J Clin Pract 2021; 75: e13762.

17. Pessoa E, Bárbara C, Viegas L, et al. Factors Associated with In-Hospital Mortality from Community-Acquired Pneumonia in Portugal: 2000-2014. BMC Pulm Med 2020; 20: 18.

18. Said M. Pneumonia. In: Rahajoe NN, Supriyatno B, Setyanto DB (eds) Buku Ajar Respirologi Anak. Jakarta: Badan Penerbit IDAI, 2008, p. 350.

19. Ferdous F, Ahmed S, Das SK, et al. Pneumonia Mortality and Healthcare Utilization in Young Children in Rural Bangladesh: A Prospective Verbal Autopsy Study. Trop Med Health 2018; 46: $1-10$.

20. Lamberti LM, Zakarija-Grković I, Fischer Walker CL, et al. Breastfeeding for Reducing the Risk of Pneumonia Morbidity and Mortality in Children under Two: A Systematic Literature Review and Meta-Analysis. BMC Public Health 2013; 13 Suppl 3: S18.

21. Siempos II, Vardakas KZ, Kyriakopoulos CE, et al. Predictors of Mortality in Adult Patients with Ventilator-Associated Pneumonia: A MetaAnalysis. Shock 2010; 33: 590-601.

22. Inchai J, Pothirat $\mathrm{C}$, Bumroongkit $\mathrm{C}$, et al. Prognostic Factors Associated with Mortality of Drug-Resistant Acinetobacter baumannii Ventilator-Associated Pneumonia. J Intensive Care 2015; 3: 9 .
23. Brown N. How Should Very Low Birthweight Babies Best be Managed in Papua New Guinea? $P$ N G Med J 1996; 12-15.

24. Diallo FB, Bell L, Moutquin J-M, et al. The Effects of Exclusive Versus Non-Exclusive Breastfeeding on Specific Infant Morbidities in Conakry (Guinea). PAMJ 2009; 22. Epub ahead of print 2009. DOI: 10.11604/PAMJ.2009.2.2.51.

25. Rudan I, Boschi-Pinto C, Biloglav Z, et al. Epidemiology and Etiology of Childhood Pneumonia. Bull World Health Organ 2008; 86: 408-416.

26. Folic N, Djordjevic Z, Folic M, et al. HospitalAcquired Pneumonia in Newborns with Birth Weight Less than 1500 Grams: Risk Factors and Causes. Serbian J Exp Clin Res 2016; 17: 327-332.

27. Bokade C, Madhura A, Bagul A, et al. Predictors of Mortality in Children due to Severe and Very Severe Pneumonia. Niger Med J 2015; 56: 287.

28. Ramachandran P, Nedunchelian K, Vengatesan A, et al. Risk Factors for Mortality in Community Acquired Pneumonia among Children Aged 1-59 Months Admitted in a Referral Hospital. Indian Pediatr 2012; 49: 889-895.

29. Zielińska M, Zleliński S, niatkowska-Bartkowska A. Mechanical Ventilation in Children-Problems and Issues. Adv Clin Exp Med 2014; 23: 843-848.

30. Jakhar SK, Pandey M, Shah D, et al. Etiology and Risk Factors Determining Poor Outcome of Severe Pneumonia in Under-Five Children. Indian $J$ Pediatr 2018; 85: 20-24. 